\title{
Improvement of glyphosate adsorption using new composites based on Ghassoul and chitosan: Kinetics and equilibrium study
}

\author{
Karim Hnana, Abdeslam Barhoun and Khalid Draoui * \\ Laboratory of Materials and Interfacial Systems, Faculty of Sciences, Abdelmalek Essaadi University, \\ PO Box 2121, 93030, Tetouan, Morocco
}

\begin{abstract}
Clay materials combined with other compounds are intensely used in several fields. The present study focuses on the synthesis of organoclays and nanocomposites based on the intercalation of surfactant and biopolymer into swelling Moroccan clay. The produced materials were used in the removal of glyphosate from the aqueous medium. The organoclay was obtained by the intercalation of cetyltrimethylammonium bromide (CTAB) in the interlamellar space of stevensite, and the nanocomposite was fabricated by the direct interaction between the stevensite and chitosan. These materials were characterized by mean X-Ray Diffraction, Fourier Transform Infra-Red Spectroscopy (FTIR), Thermal Analysis and Transmission Electron Microscopy (TEM). The results showed that the stevensite is the dominant clay mineral of Ghassoul and confirmed that the nanocomposite has an intercalated clay structure. The batch mode was accomplished to quantify the glyphosate removal capacity from aqueous solution by these materials. The enhancement of hydrophobic properties has promoted the retention of the herbicide. The pseudo-second-order kinetic model of adsorption was the most suitable to describe the process of adsorption and the Freundlich isotherm equation fitted satisfactory the adsorption isotherm data. The capacity of adsorption was more outstanding for the nanocomposite chitosan/Ghassoul and reached a significant value of $159.10 \mathrm{mg} \cdot \mathrm{g}^{-1}$. The nanocomposites based on chitosan/Ghassoul could be considered as promising materials for treatments of pesticide-contaminated water.
\end{abstract}

Keywords: Ghassoul clay; chitosan; glyphosate; composite; Kinetics; adsorption isotherm.

\section{Introduction}

Modern agriculture relies on agrochemical products like pesticides and fertilizers to ensure the yields of cultures and harvests quality. The usefulness and the necessity of chemical pesticides to increase global agricultural productivity have been widely demonstrated. Nevertheless, these synthetic products have a harmful impact on the biodiversity of ecosystems and contaminate the different water resources, if the active molecules leave the application sites. Therefore, they constitute a severe threat to the environment.

Glyphosate is an extremely effective broad-spectrum, post-emergence and non-selective herbicide, and persistent in the environment ${ }^{~}{ }^{\text {. It is derived from an }}$ acid amine (glycine), belonging to the family of aminophosphates ${ }^{2,3}$. It was discovered in 1970 by a group of the Company Monsanto and put on the market in 1974 under the name Roundup ${ }^{4}$. Glyphosate is widely used in agriculture, and there is currently a great deal of concern about its impact on the deterioration and degradation of the environment.

*Corresponding author: Khalid Draoui

Email address: khdraoui@gmail.com

DOI: http://dx.doi.org/10.13171/mjc9419111121087kd
It is incorporated via various routes during its manufacture, use and runoff after use ${ }^{5-7}$.

Moreover, it is considered as one of the most dangerous herbicides that cause serious problems and can lead to human poisoning. According to the Globally Harmonized System of Classification and Labelling of Chemicals ${ }^{8}$, this herbicide is considered to be highly toxic to aquatic life with long-lasting effects. The enormous amount of pesticides used and their high toxic effect has conducted the scientific community to investigate the efficiency of several processes in their elimination such as photodegradation, biological degradation, ionic exchange, ultrafiltration, electrochemical extraction, membrane filtration and adsorption. Among them, adsorption is the most simple, practical, and economical technique. Many researchers have studied the use of a various family of adsorbents, such as activated carbon ${ }^{9}$, industrial water residues ${ }^{10}$, chitosan/diatomaceous earth ${ }^{11-12}$, bioadsorbent bead 13 and clay materials ${ }^{14}$ for the elimination of glyphosate from contaminated water. Others authors have synthesized materials for its degradation or photodegradation ${ }^{15}$. Clays are considered an

Received September 26, 2019 Accepted October 9, 2019 Published November 12, 2019 
inexpensive resource, abundant materials, easily available, non-toxic and mechanically and chemically stable. Moreover, their cationic exchange capacity (CEC) and specific surface area (SSA) are very important, especially for swelling clays as montmorillonite and stevensite ${ }^{16}$.

These natural mineral resources have led to a great interest of researchers. They can be used as natural materials with high efficiency of adsorbing organic or inorganic pollutants from aqueous solutions. Thus, they are promising for controlling environmental pollution ${ }^{17,18}$. The specific clay, which we have chosen in this study, is Moroccan stevensite. This clay mineral is the principal constituent of the locally called "Ghassoul" clay. The deposits of Ghassoul are unique in the world and exploited in the Tertiary lacustrine basin of the Jbel Ghassoul located in the east side of the middle Atlas Mountains of Morocco ${ }^{19}$. In recent years, the characterization and application of Moroccan Ghassoul clay have attracted the interest of various researchers ${ }^{16,20}$. Generally, clay minerals have a low affinity towards hydrophobic or non-ionic organic molecules. To overcome these limitations, the intercalation of surfactants into the clay gallery is the most important way cited in the literature ${ }^{21,22}$. The surfactant takes places of interlamellar compensation cations creating a stable organic phase. This change leads to a transformation from hydrophilic to hydrophobic characteristic and a wide range of new and beneficial properties. The obtained hybrid materials could be used as an adsorbent for the removal of persistent organic pollutants ${ }^{21,22}$. Their adsorptive properties are closely linked to the amount and the length of the aliphatic chain of incorporated surfactant. Azejjel et al ${ }^{22}$ have found that the adsorption of terbutryn is drastically improved by the organoclays based on the intercalation of TMA, OTMA and ODTMA surfactants in Moroccan clay. Other work reported that the modified clay Cloisite is efficient for the retention of penconazole, chlorpyrifos and metalaxyl ${ }^{23}$.

Recently, composites and nanocomposites based on chitosan and clays have received considerable attention regarding the improvement of adsorption, mechanical properties, and chemical stability. Chitosan is a copolymer composed of linked 2acetamido-2-deoxy-d-glucopyranose and 2-amino-2deoxy-d-glucopyranose. It is obtained by deacetylation of chitin and considered one of the most available natural polymers on earth ${ }^{24}$. Because of its excellent biocompatibility, biodegradability, and multiple functional groups, chitosan has attracted significant interest in a broad range of applications such as water treatment, separation membrane, food package, and tissue engineering 25. Chitosan is an excellent natural adsorbent in that its amine ( $\mathrm{NH} 2)$ and hydroxyl $(\mathrm{OH})$ groups may serve as potential coordination sites to form complexes with various heavy metal ions. It can effectively remove metal ions by adsorptive enrichment. However, its low mechanical properties restrict its use in a wide range of application. Nanocomposite technology using clay minerals at low loading has already been proven to be an effective way to overcome the problems $26^{-28}$. Several methods have been developed to improve the dispersion of clay minerals, based on two principal ways of modification: physical adsorption and chemical modification, such as grafting functional polymers or functional groups on the surface of clay or ion exchange with organic cations or anions ${ }^{29,30}$.

The composite can be obtained with different morphology as powder or bead. Its proprieties are governed by the chitosan/clay ratio and the state of clay mineral exfoliation and dispersion. Several studies have confirmed the net improvement of metals, dyes or pesticides adsorption onto these modified materials ${ }^{31,32}$.

The present work aims to evaluate the efficiency of Ghassoul modification by cationic surfactant CTAB and biopolymer chitosan toward the elimination of glyphosate from aqueous solution. The novel organoclays were characterized by several techniques to confirm the intercalation of organic compounds in the interlamellar space. The improvement of adsorption properties was investigated by the comparison of glyphosate adsorption capacity with unmodified Ghassoul.

\section{Experimental}

\subsection{Materials}

The Ghassoul clay (stevensite) used in this work was sampled in the Tertiary basin of Missour at the East side of the Middle Atlas Mountains (Morocco). The raw clay was crushed and sieved to obtain particles below $\quad 100 \mu \mathrm{m}$. Cationic surfactant Hexadecyltrimethylammonium bromide (CTAB) $95 \%$, Chitosan medium molecular weight (Cts) and Glyphosate were supplied by Sigma Aldrich® and used without further purification.

\subsection{Preparation of modified Ghassoul}

The synthesis of organic Ghassoul was performed according to a procedure developed elsewhere ${ }^{33}$. The interlamellar clay space was homogenized by dispersion of raw clay (particle below $100 \mu \mathrm{m}$ ) in $\mathrm{NaCl}$ medium at a concentration of $100 \mathrm{meq} / 100 \mathrm{~g}$. The solution was stirred for 4 hours. The exchanged clay mineral was recuperated by centrifugation at $4500 \mathrm{rpm}$ during 20 minutes and watched with deionized water until free of chloride ions. Then 0.4 $\mathrm{g}$ of homogenized Ghassoul was dispersed in $200 \mathrm{~mL}$ of deionized water containing $0.2 \mathrm{~g}$ of cetyltrimethylammonium bromide (CTAB). The suspension was shaken for 3 hours at $60^{\circ} \mathrm{C}$, using a magnetic stirrer, and then centrifuged. The obtained product was washed several times up to the total elimination of bromide ions and surfactant excess, dried in an oven at $60^{\circ} \mathrm{C}$, crushed in a mortar and then kept in closed desiccators until use.

The chitosan solution was prepared using a $1 \%$ acetic acid solution. $2 \mathrm{~g}$ of chitosan was dissolved in $200 \mathrm{~mL}$ 
of acetic acid solution with agitation for 5 hours to obtain a homogeneous mixture. Afterwards, $2 \mathrm{~g}$ of clay was added into $100 \mathrm{~mL}$ of chitosan solution and was stirred for another $5 \mathrm{~h}$. The $\mathrm{pH}$ of chitosan/clay solution was adjusted to 4.7, and then $1 \mathrm{~N}$ sodium hydroxide solution was added dropwise to reach the neutralization and to eliminate the acid excess. The obtained nanocomposite was washed and centrifuged at $9000 \mathrm{rpm}$ for $15 \mathrm{~min}$. The product was dried in the oven at $70^{\circ} \mathrm{C}$.

\subsection{Characterization instruments}

$\mathrm{X}$-ray diffraction Characterization (XRD) was carried out by a Bruker D8 Advance diffractometer using the $\mathrm{Cu}-\mathrm{K} \alpha$ radiation (wavelength $\lambda=1.5404 \AA$ ) to identify the clay minerals of the raw Ghassoul and their transformation after modification. XRD patterns of clays powder were recorded between 3 and $80^{\circ}$ with a step size of $0.05^{\circ}$. Thermogravimetric analysis (TGA) of the samples was performed on a TA Instruments - Waters LLC, SDT Q600 analyzer with a heating rate of $5^{\circ} \mathrm{C} \mathrm{min}^{-1}$ under dry airflow (100 $\left.\mathrm{mL} \cdot \mathrm{min}^{-1}\right)$. The morphology of different samples was investigated by Transmission Electron Microscopy (TEM) measurements performed on a JEOL100CX microscope. Samples, in the form of bulk powders, were dispersed in ethanol and then deposited on specific grids (400 mesh copper grids covered with an ultrathin carbon membrane of 2-3 nm thickness). Fourier transform infrared spectra (FTIR) were conducted on Nicolet Nexus 470 Fourier Transform Infrared spectrometer by using $\mathrm{KBr}$ pressed disk technique. The spectra were collected for each measurement over the spectral range of 400-4000 $\mathrm{cm}^{-1}$ with a resolution of $1 \mathrm{~cm}^{-1}$. The UV absorption spectra reported in this work for glyphosate dosage have been recorded by using a double-beam Varian Cary 500 UV-Vis spectrophotometer

\subsection{Adsorption experiments}

The adsorption experiments were performed in batch mode at room temperature. $200 \mathrm{mg}$ of adsorbent was added to $20 \mathrm{~mL}$ of glyphosate solution at the desired concentration. The solution was then stirred to equilibrium. After separation by centrifugation at $4500 \mathrm{rpm}$ during 20 minutes, the remaining concentration of glyphosate in the supernatant was determined by using UV-visible spectrophotometer (Varian Cary 500 UV-Vis).

\section{Results and discussion}

\subsection{Characterization of samples}

\subsubsection{XRD analysis}

The XRD patterns were obtained on the powder of Ghassoul clay (Stv), Ghassoul modified by CTAB (Stv-CTAB) and Ghassoul modified by chitosan (Stv-
Cts). The results are listed in Figure 1. Significant changes occur in the XRD peaks of the raw Ghassoul after modification with CTAB surfactant and chitosan biopolymer. The (001) diffraction peak of Ghassoul has occurred at $2 \theta$ value of $5.88^{\circ}$, which is related to $\mathrm{d}_{001}$ stevensite basal spacing of $1.5 \mathrm{~nm}^{34}$. In contrast, the $\mathrm{d}_{001}$ peak of modified stevensite by chitosan appeared at $2 \theta$ of $4.93^{\circ}$, which corresponds to an interlamellar space $\mathrm{d}_{001}$ of $1.79 \mathrm{~nm}$. The stevensite belongs to 2:1 clay group with layer thickness about $0.98 \mathrm{~nm}$. The increase of the basal spacing is estimated at $0.81 \mathrm{~nm}$. Chitosan should be under monolayer conformation 35,36 . For the surfactant CTAB hybrid clay, the $\mathrm{d}_{001}$ value was about $1.98 \mathrm{~nm}$ $\left(2 \theta=4.46^{\circ}\right)$. This value is higher than of the stevensite-chitosan composite. Different conformations of surfactant in the lamellar gallery are possible as cited in the literature ${ }^{22}$. Therefore, the XRD analysis has clearly shown the success of the intercalation of CTAB and chitosan into the stevensite gallery.

\subsubsection{FTIR spectroscopy analysis}

Fourier Transform Infrared (FTIR) spectroscopy study of Ghassoul (Stv) and modified Ghassoul (StvCTAB, Stv-Cts) was carried out. The obtained results are given in Figure 2. The spectra of Ghassoul show, in general, the characteristics absorption regions of clay materials ${ }^{37}: 3700-3600 \mathrm{~cm}^{-1}$ corresponding to the stretching vibration of the structural $\mathrm{OH}$ group of silicates, $3500-3200 \mathrm{~cm}^{-1}$ and $1663-1636 \mathrm{~cm}^{-1}$ corresponding to the vibration of stretching and bending of the adsorbed water molecules respectively. The bands from 1040 to $600 \mathrm{~cm}^{-1}$ are assigned to vibrations of $\mathrm{Si}-\mathrm{OH}, \mathrm{Al}-\mathrm{OH}$ and $\mathrm{Al}-\mathrm{O}-\mathrm{Al}$ groups. For clays studied in this work, these bands appear respectively at the frequencies $3621,3436,1635$ and $1011 \mathrm{~cm}^{-1}$ for the stevensite, 3679, 3424, 1639 and $1011 \mathrm{~cm}^{-1}$ for the Stv-Cts and 3679, 3424, 1636 and $1011 \mathrm{~cm}^{-1}$ for the Stv-CTAB. The band at $1450 \mathrm{~cm}^{-1}$ is due to the carbonates. The spectra of stevensite modified by chitosan (Stv-Cts) present the fingerprint of both stevensite and chitosan at $1654 \mathrm{~cm}^{-1}$ which corresponds to amide I stretching vibration, at 1588 $\mathrm{cm}^{-1}$ which is attributed to blending vibration of the amide II, and the peak at $1420 \mathrm{~cm}^{-1}$ which was related with stretching vibration of primary alcoholic groups in chitosan ${ }^{38}$. Also, the FTIR spectra of the stevensite modified by CTAB (Stv-CTAB) revealed the appearance of new vital bands in the regions 3000$2800 \mathrm{~cm}^{-1}$ and $1500-1300 \mathrm{~cm}^{-1}$, attributed to the vibration of stretching and deformation of $\mathrm{CH}{ }^{37}$. These bands appear respectively at the frequencies 2920, 2850 and $1469 \mathrm{~cm}^{-1}$. The FTIR results are consequently in good agreement with the XRD analysis. 

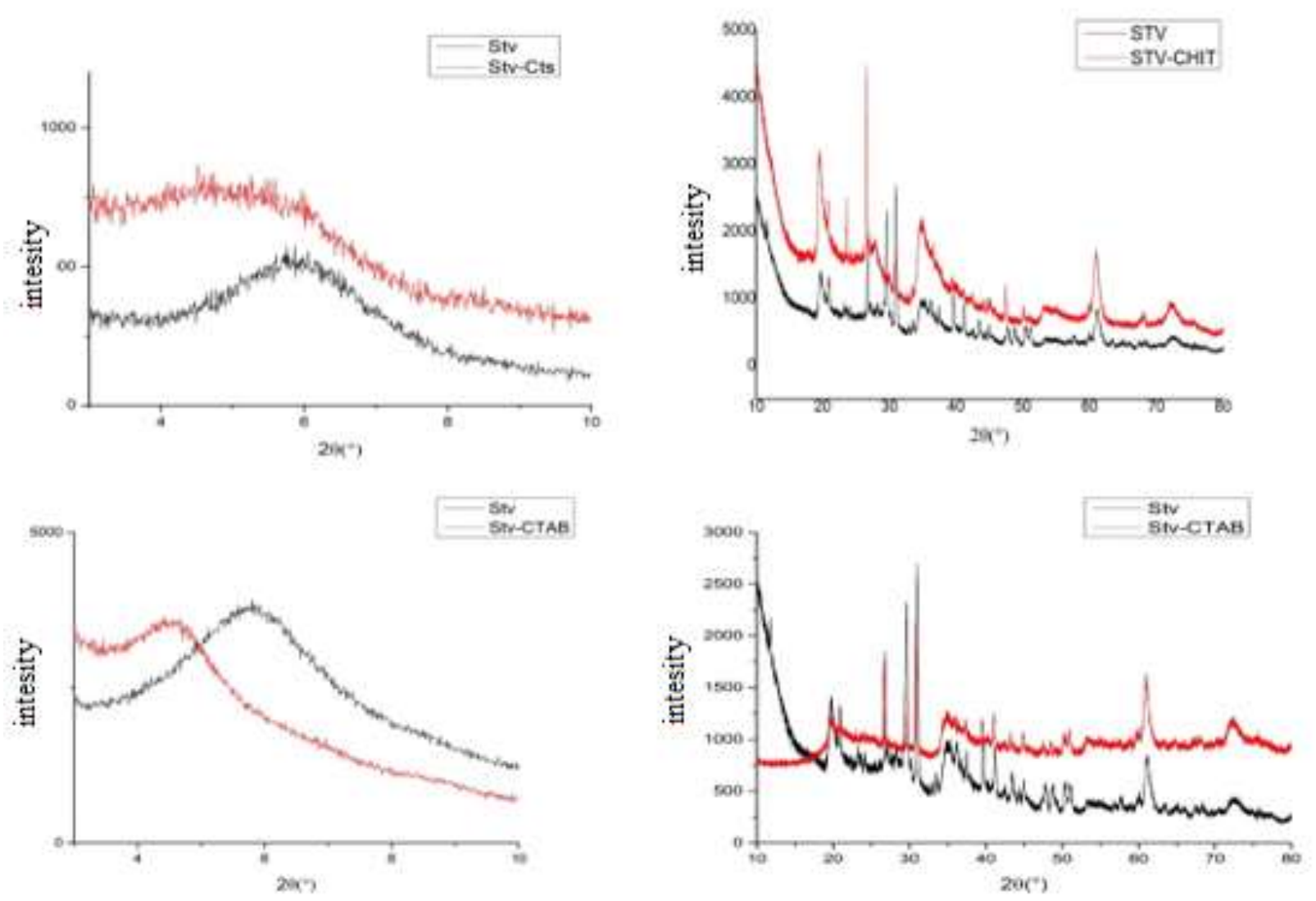

Figure 1. XRD patterns of Ghassoul (Stevensite), Stv-CTAB. and Stv-Cts

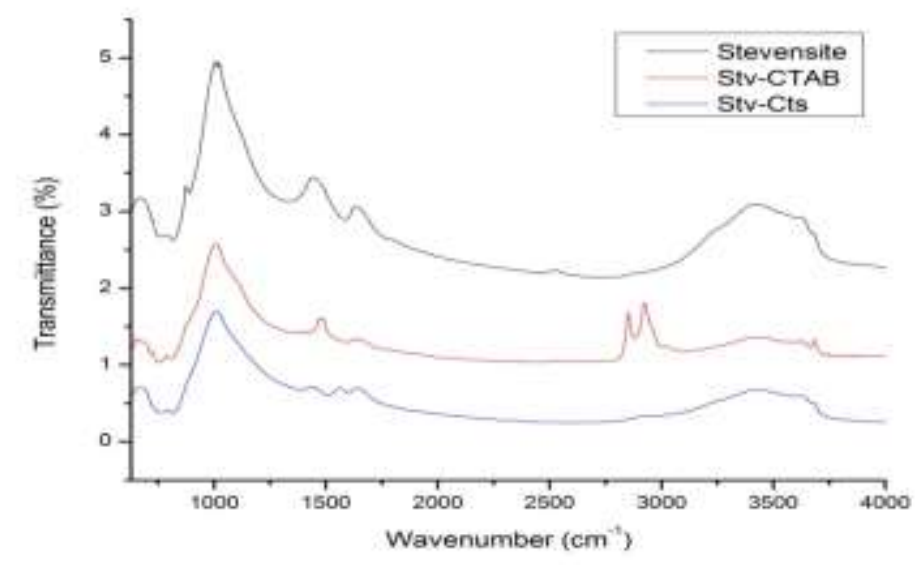

Figure 2. FT-IR spectra of stevensite, Stv-Cht and Stv-CTAB

\subsubsection{Thermal analysis}

The thermal stability of the samples was studied by thermogravimetric analysis (TGA/DTG). The thermogram curves of Stv, CTAB-Stv and Cts-Stv are shown in Figure 3. TGA curves show three ranges of weight loss. From 50 to $180{ }^{\circ} \mathrm{C}$, the weight loss is attributed to the departure of adsorbed water, and interfoliaire water. It's of the order of $14 \%, 7 \%$ and $2.5 \%$ for Stv, Stv-Cts and Stv-CTAB respectively. This result confirms the hydrophilic properties of stevensite and hydrophobic properties of modified stevensite. The important region to confirm the intercalation of organic matter onto the clay is between 200 and $500{ }^{\circ} \mathrm{C}$. For raw stevensite, there is no loss of weight, confirming the absence of organic matter. However, loss of weight-related to Cts-Stv and stv-CTAB, is of the order of $9.55 \%$ and $18 \%$ respectively. This significant loss is attributed to the organic matter decomposition according to the incorporation of CTAB and Cts in the clay matrix. Thermal dehydroxylation of Stv and organic carbon decomposition of the organoclay structures are observed in the range of $500-750^{\circ} \mathrm{C}$ which corresponds to the loss of weight about $12 \%, 4.1 \%$ and $11.9 \%$ respectively. 

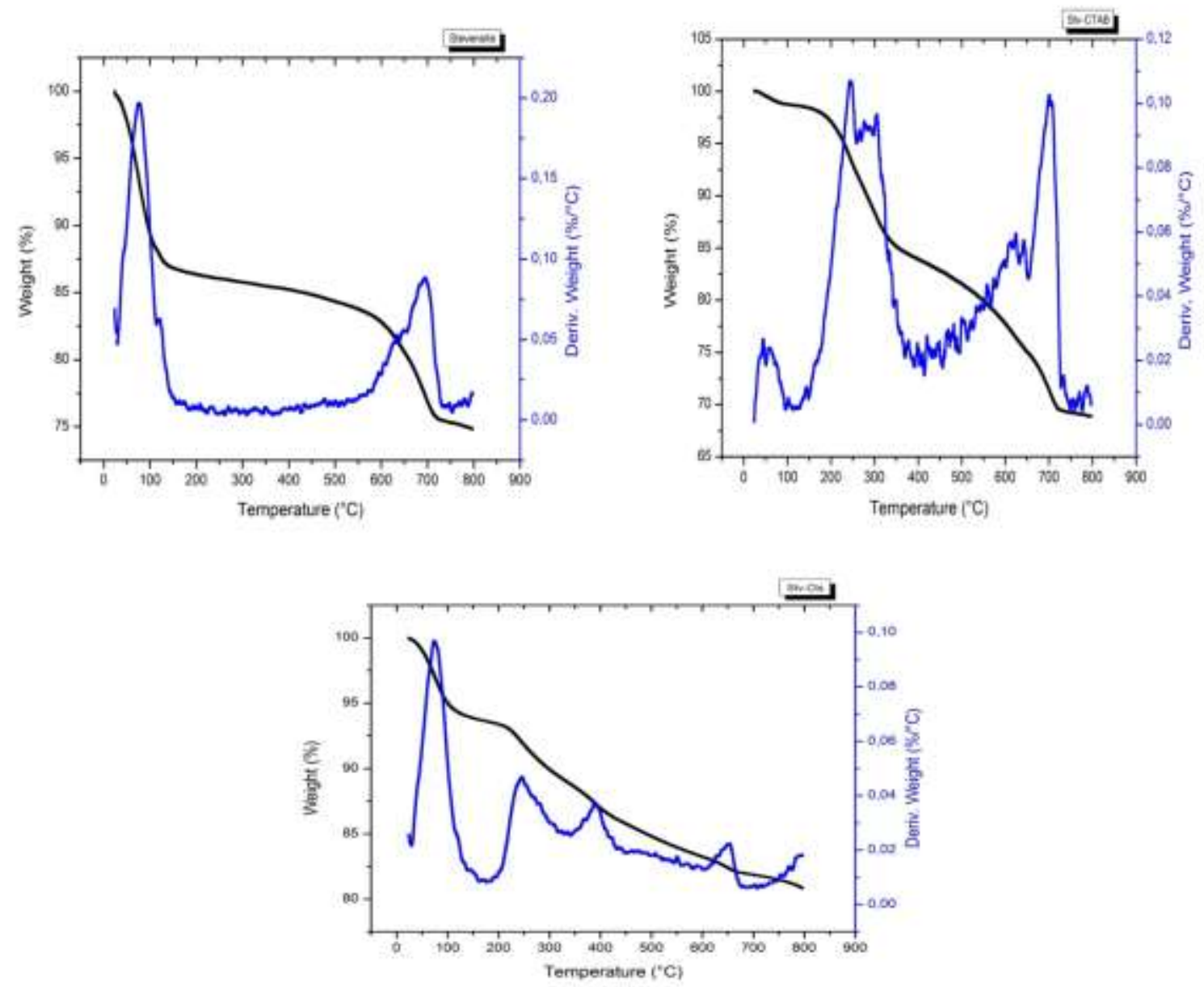

Figure 3: Thermograms curves TGA/DTG of stevensite, Stv-CTAB and Stv-Cht

\subsubsection{TEM study}

The TEM images of the samples are given in Figures $4(\mathrm{a}, \mathrm{b}, \mathrm{c})$. For raw Ghassoul, the TEM micrographs allow clearly to visualize the layers of the platelets. The $\mathrm{d}_{001}$ value measured in different regions of the image is in harmony with the value determined by $\mathrm{XRD}\left(\mathrm{d}_{001}=1.5 \mathrm{~nm}\right)$. The lamellar structure is also observed with the chitosan-stevensite nanocomposite.
The interlamellar space is slightly higher than the pristine stevensite. The obtained nanocomposite is not exfoliated but it's seems to be an intercalated composite. We also note that CTAB-stevensite has preserved its lamellar structure with a larger space. Consequently, the modification of Ghassoul by chitosan and CTAB have conducted to the intercalated materials.
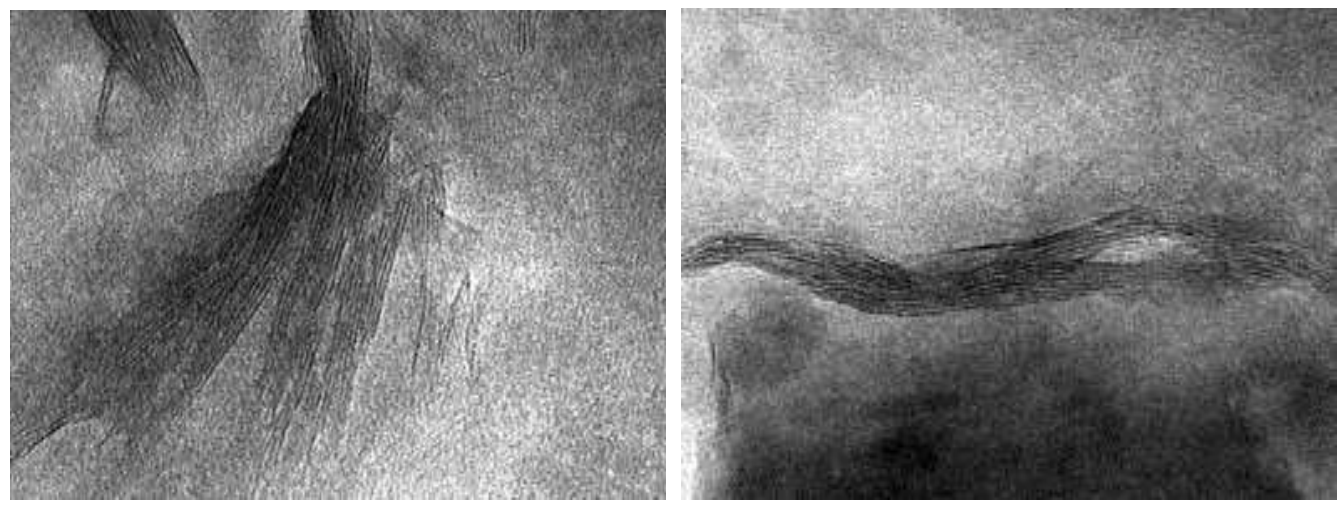

(a) stevensite 

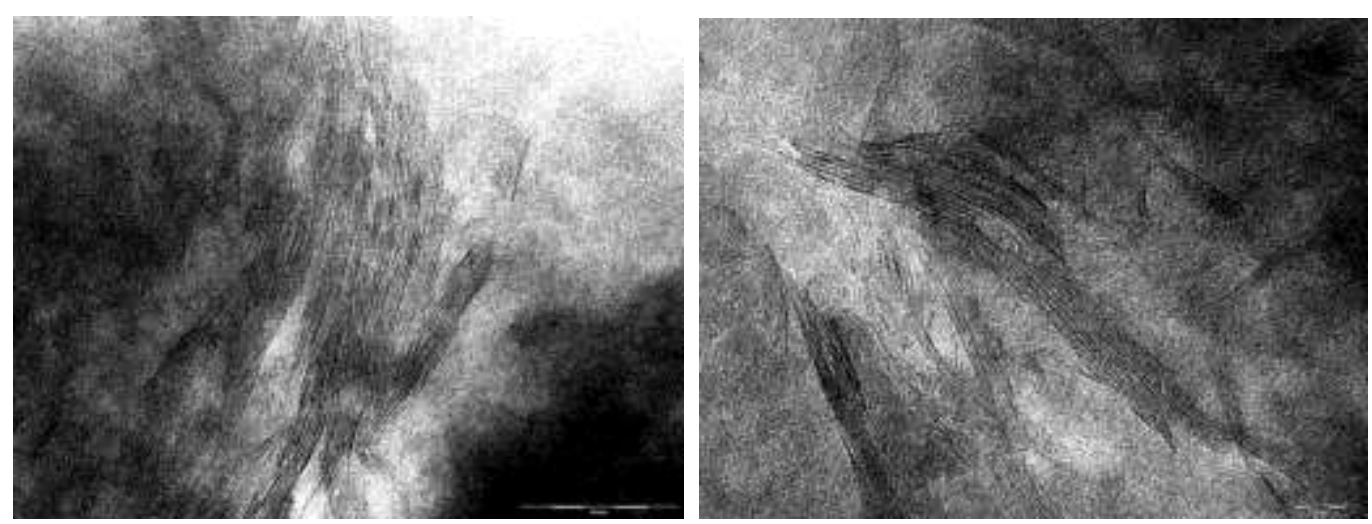

\section{(b) Stv-Cts}
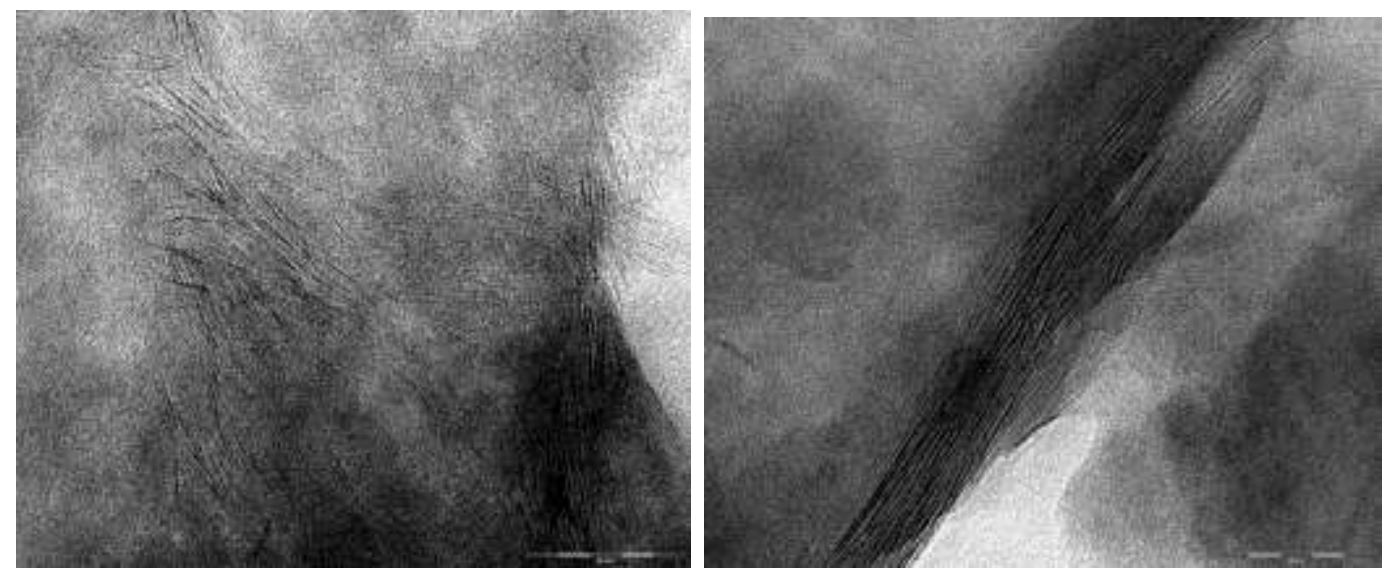

(c)Stv-CTAB.

Figure 4. TEM images of stevensite, Stv-Cst and Stv-CTAB

\subsection{Adsorption kinetics}

The determination of the time necessary to reach equilibrium is essential to elucidate the required conditions for the adsorption process. In order to investigate this parameter, the glyphosate adsorption on the stevensite, Stv-CTAB and Stv-Cts were conducted as a function of contact time in a range of 0 to $300 \mathrm{~min}$. The glyphosate concentration was $5 \times 10^{-}$
${ }^{3} \mathrm{M}$. Figure 5 shows the influence of contact time on adsorption capacity of the modified and unmodified Ghassoul. The process can be divided into two parts, the first of which the adsorption capacity progressively increases with the contact time. After $150 \mathrm{~min}$, the adsorption becomes smooth and steady, owing to the decrease of adsorption sites on the adsorbent surface.

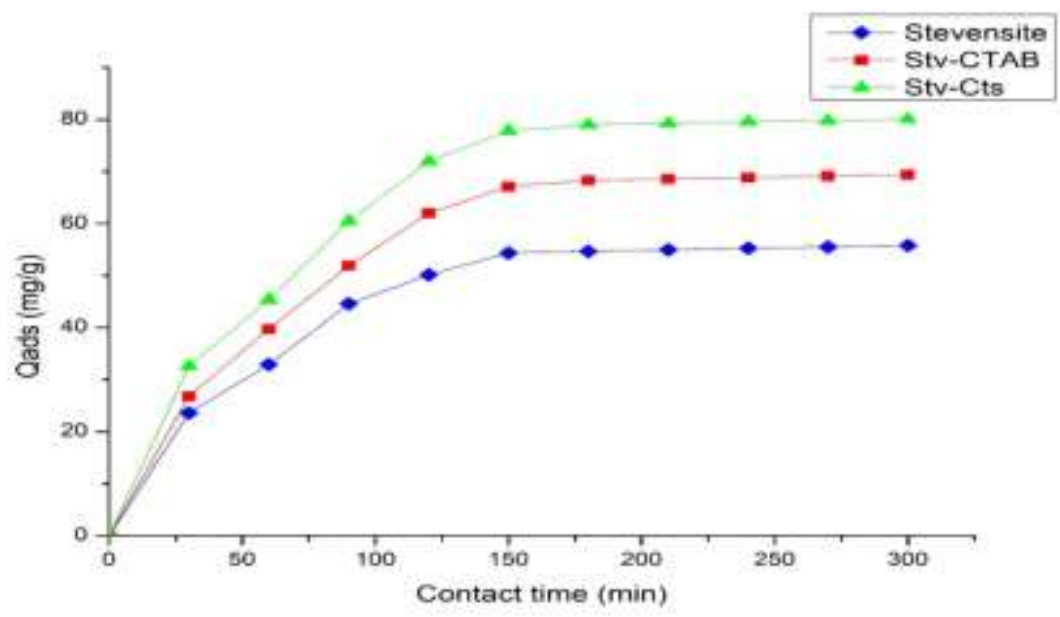

Figure 5. Effect of contact time on the adsorption of glyphosate on stevensite, Stv-Cts and Stv-CTAB 
Under the operating kinetic conditions, the composite Stv-Cts displays the highest value of adsorbed amount followed by hybrid Ghassoul, Stv-CTAB. In order to clarify the kinetic process, three models were used: pseudo-first-order, pseudo-second-order and, intraparticle diffusion model.

The linear form of pseudo-first-order model is expressed as ${ }^{39,40}$ :

$\log \left(Q_{e}-Q_{t}\right)=\log Q_{e}-\frac{k_{1}}{2.303} t$
Where, Qe: Quantity of adsorbed glyphosate at the equilibrium time per gram of adsorbent $\left(\mathrm{mg}^{\mathrm{g}} \mathrm{g}^{-1}\right), \mathrm{Q}_{\mathrm{t}}$ : the quantity adsorbed at any time $(\mathrm{mg} / \mathrm{g}), \mathrm{k}_{1}$ : the pseudo first-order rate kinetic $\left(\mathrm{min}^{-1}\right)$.

The result obtained is shown in Figure 6. The correlation coefficient $\mathrm{R}^{2}$ values determined were less than 0.9 (Table 1) and the calculated Qe are not in agreement with the experimental data. Therefore, pseudo-first-order kinetics is not the appropriate model for the glyphosate adsorption on the studied samples.

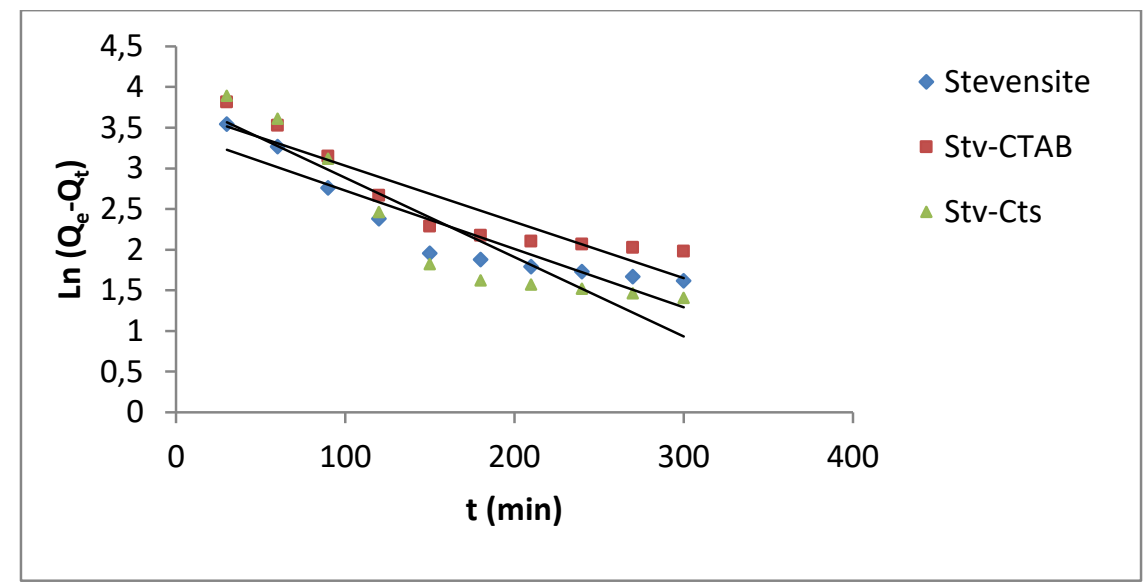

Figure 6. Pseudo-first order kinetic model for the adsorption of glyphosate on stevensite, Stv-Cts and Stv-CTAB.

The linear form of the pseudo-second-order model is given by the equation ${ }^{41,42}$ :

$\frac{\mathrm{t}}{\mathrm{Q}_{\mathrm{t}}}=\frac{1}{\mathrm{k}_{2} \mathrm{qQ}_{\mathrm{e}}^{2}}+\frac{1}{\mathrm{Q}_{\mathrm{e}}} \mathrm{t}$

$\mathrm{k}_{2}$ represents the pseudo-second order rate constant $\left(\mathrm{g} \cdot \mathrm{mg}^{-1} \cdot \mathrm{min}^{-1}\right)$.

Figure 7 shows a linear variation of $\mathrm{t} / \mathrm{Q}_{\mathrm{t}}$ as a function of $\mathrm{t}$. The correlation coefficients $\mathrm{R}^{2}$ are very close to unity and the $\mathrm{Q}_{\mathrm{e}}$ predicted values agree with the experimental data Table 1 . This result leads to conclude that the pseudo-second-order model fits well the kinetic data for the three adsorbents. Therefore, the chemisorption process should be the rate-limiting step $^{41-42}$. Consequently, the adsorption mechanism is governed by electrostatic attraction and chemical bonding between the materials and glyphosate.

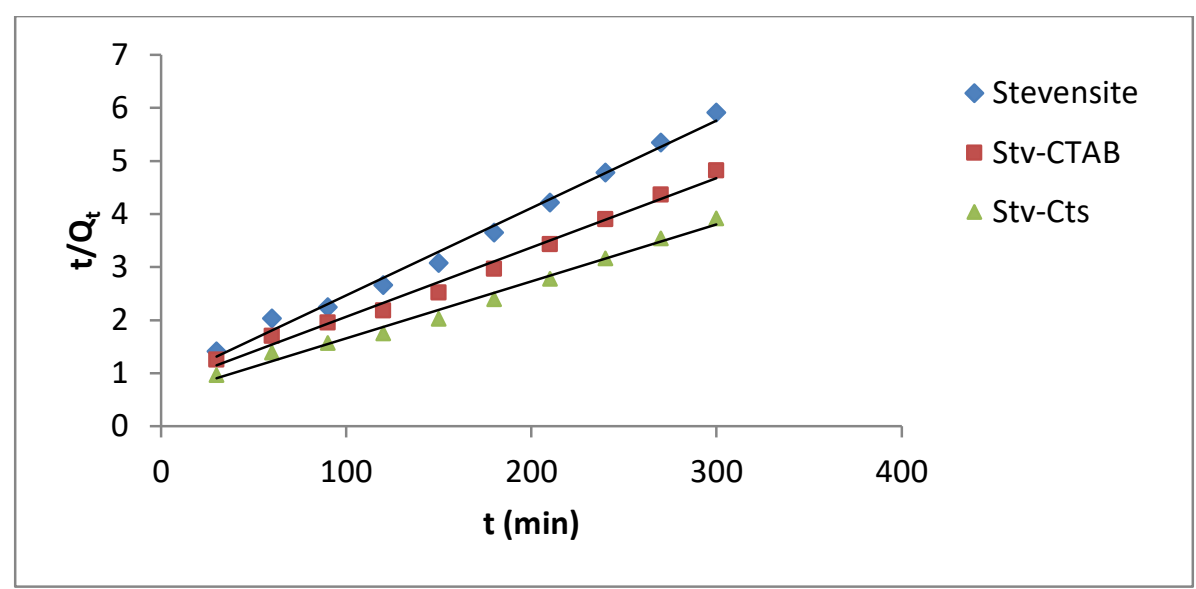

Figure 7. Pseudo- second-order kinetic model for the adsorption of glyphosate on stevensite, Stv-Cts and Stv-CTAB.

The model of Elovich is also used to describe the chemisorptions and heterogeneity of the surface. This model is expressed according to the following equation called equation of Elovich ${ }^{43}$, which is given by 
$\frac{\mathrm{dq}_{\mathrm{t}}}{\mathrm{dt}}=\alpha \mathrm{e}^{\left(-\beta \mathrm{q}_{\mathrm{t}}\right)}$

Where $\alpha\left(\mathrm{mg} \cdot \mathrm{g}^{-1} \cdot \mathrm{min}^{-1}\right)$ is the initial rate of the adsorption, while $\beta\left(\mathrm{g} . \mathrm{mg}^{-1}\right)$ is the constant of the desorption linked to the length of the surface coverage and the activation energy for the chemisorption. The simplified form of Elovich equation ${ }^{43}$ leads to the following expression:

$Q_{t}=\frac{1}{\beta} \ln (\alpha \beta)+\frac{1}{\beta} \ln t$

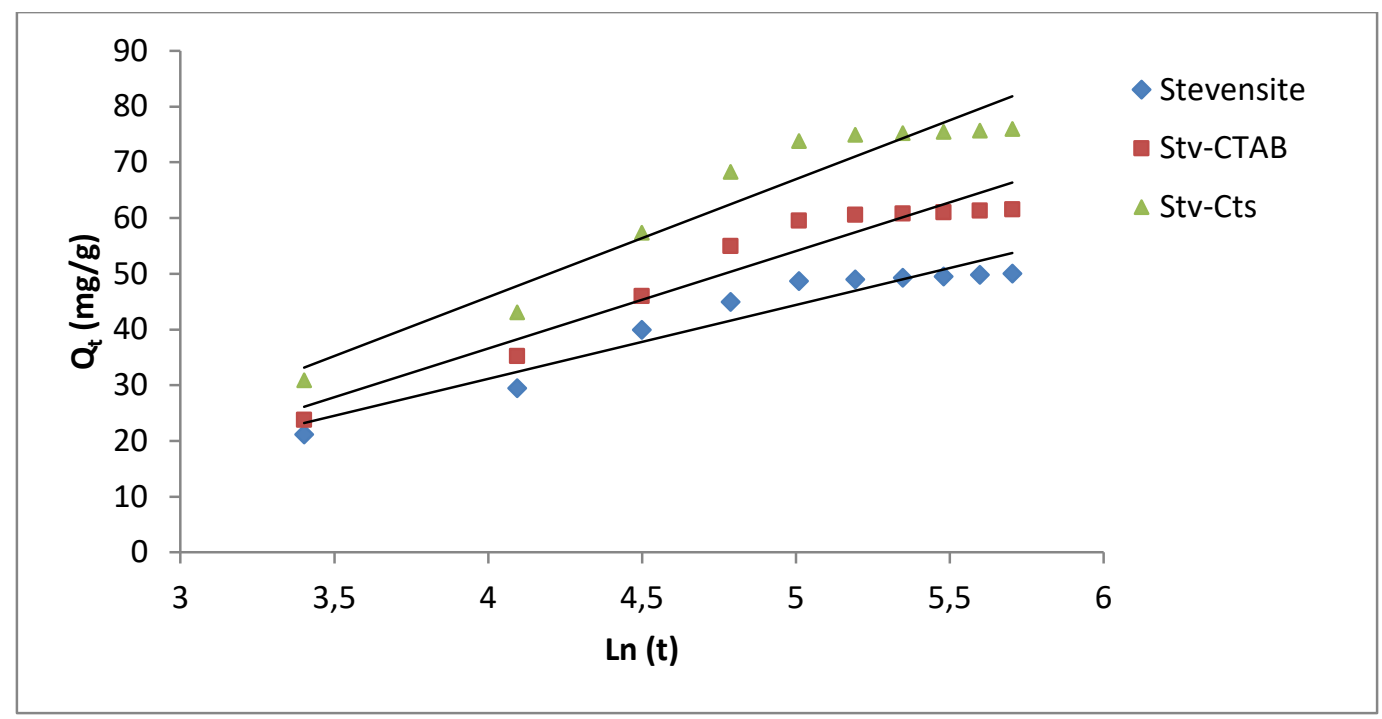

Figure 8. Elovich kinetic model for the adsorption of glyphosate on stevensite, Stv-Cts and Stv-CTAB.

$\alpha$ and $\beta$ values are listed in Table 1 . The results presented in Fig. 8 shows that the Elovich equation is not suitable to describe the kinetic mechanism. Indeed, the correlation coefficient $\mathrm{R}^{2}$ values are less than those obtained for the pseudo-second-order model (Table 1).

Adsorption process may occur by several steps. In order to identify the mechanism governing the adsorption during the transport of adsorbate from solution to adsorption sites, the intraparticle diffusion model is frequently used. According to Webber and Morris ${ }^{44}$, the linear form of the intra-particle equation is expressed by :

$\mathrm{Q}_{\mathrm{t}}=\mathrm{K}_{\mathrm{i}} \cdot \mathrm{t}^{1 / 2}+\mathrm{C}$

$\mathrm{K}_{\mathrm{i}}$ represent the intra-particle diffusion rate constant $\left(\mathrm{mg} / \mathrm{g} \cdot \mathrm{min}^{1 / 2}\right)$. When the variation of $\mathrm{Q}_{\mathrm{t}}$ as a function of $\mathrm{t}^{1 / 2}$ goes through the origin, the intra-particle diffusion should be the only rate-limiting step. C indicates the thickness of the boundary layer; it does correspond to the value of the y-intercept.

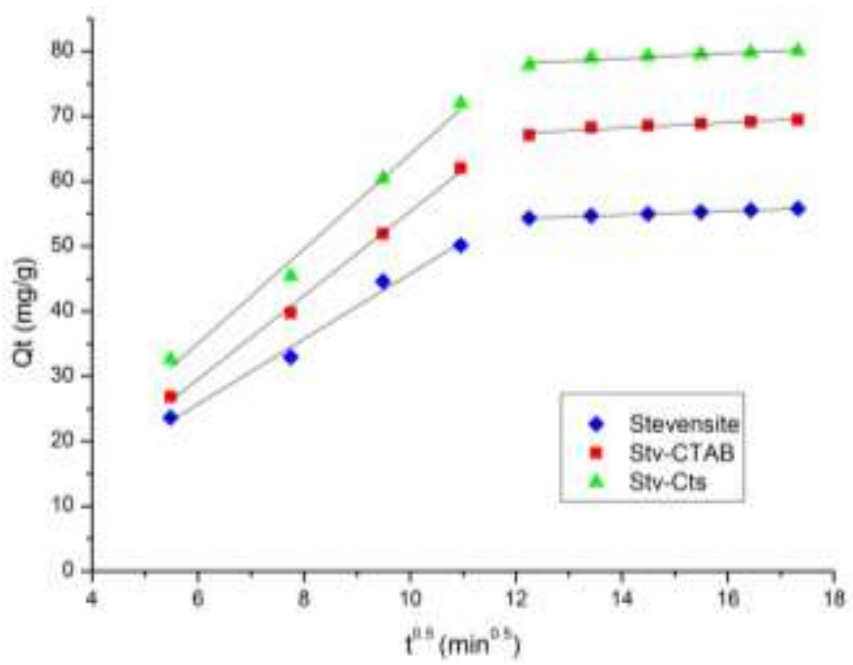

Figure 9. Weber-Morris kinetic model for the adsorption of glyphosate on stevensite,

Stv-Cts and Stv-CTAB

The plot of $Q_{t}$ versus $t^{1 / 2}$ is shown in Figure 9. The calculated kinetic parameters are summarized in Table 1. The linear plots do not intercept the origin.
The presence of two linear sections is observed for the adsorption process. This indicates that the adsorption mechanism is mainly controlled by two phases. The 
first step is a rapid increase of adsorbed amount and is related to the mass transfer to the outer surface of the clay while the slow second step corresponds to the intra-particle diffusion.

Table 1. The kinetic parameters of the models of Lagergren pseudo first and second order, Elovich and WeberMorris.

\begin{tabular}{|c|c|c|c|c|}
\hline Models & Parameters & Stevensite & Stv-CTAB & Stv-Cts \\
\hline $\begin{array}{l}\text { Pseudo-first } \\
\text { order }\end{array}$ & $\begin{array}{l}\mathrm{R}^{2} \\
\mathrm{~K}_{1}\left(\mathrm{~min}^{-1}\right) \\
\mathrm{Q}_{\mathrm{e}}\left(\mathrm{mg} \cdot \mathrm{g}^{-1}\right) \exp \\
\mathrm{Q}_{\mathrm{e}}\left(\mathrm{mg} \cdot \mathrm{g}^{-1}\right) \mathrm{cal}\end{array}$ & $\begin{array}{l}0.87 \\
0.0069 \\
55.80 \\
31.31\end{array}$ & $\begin{array}{l}0.86 \\
0.0072 \\
69.42 \\
41.49\end{array}$ & $\begin{array}{l}0.86 \\
0.0097 \\
80.07 \\
47.45\end{array}$ \\
\hline $\begin{array}{l}\text { Pseudo-second } \\
\text { order }\end{array}$ & $\begin{array}{l}\mathrm{R}^{2} \\
\mathrm{~K}_{2}\left(\mathrm{~g} \cdot \mathrm{mg}^{-1} \cdot \mathrm{min}^{-1}\right) \\
\mathrm{Q}_{\mathrm{e}}\left(\mathrm{mg} \cdot \mathrm{g}^{-1}\right) \exp \\
\mathrm{Q}_{\mathrm{e}}\left(\mathrm{mg} \cdot \mathrm{g}^{-1}\right) \mathrm{cal}\end{array}$ & $\begin{array}{l}0.99 \\
0.0003 \\
55.80 \\
58.60\end{array}$ & $\begin{array}{l}0.99 \\
0.0002 \\
69.42 \\
74.33\end{array}$ & $\begin{array}{l}0.99 \\
0.0002 \\
80.07 \\
85.45\end{array}$ \\
\hline Elovich & $\begin{array}{l}\mathrm{R}^{2} \\
\alpha\left(\mathrm{mg}^{-1} \cdot \mathrm{min}^{-1}\right) \\
\beta\left(\mathrm{g} \cdot \mathrm{mg}^{-1)}\right.\end{array}$ & $\begin{array}{l}0.93 \\
0.0069 \\
0.0756\end{array}$ & $\begin{array}{l}0.93 \\
0.0072 \\
0.0572\end{array}$ & $\begin{array}{l}0.92 \\
0.0097 \\
0.0472\end{array}$ \\
\hline Weber-Morris & $\begin{array}{l}\mathrm{R}_{1}^{2} \\
\mathrm{~K}_{1}\left(\mathrm{mg} \cdot \mathrm{g}^{-1} \cdot \mathrm{min}^{-1 / 2}\right) \\
\mathrm{R}_{2}^{2} \\
\mathrm{~K}_{2}\left(\mathrm{mg} \cdot \mathrm{g}^{-1} \cdot \mathrm{min}^{-1 / 2}\right)\end{array}$ & $\begin{array}{l}0.99 \\
4.49 \\
0.99 \\
0.26\end{array}$ & $\begin{array}{l}0.99 \\
5.71 \\
0.94 \\
0.35\end{array}$ & $\begin{array}{l}0.99 \\
6.89 \\
0.92 \\
0.37\end{array}$ \\
\hline
\end{tabular}

\subsection{Isotherm models}

The adsorption isotherm is a simple but essential tool for characterizing the nature of interactions between solute and adsorbent to predict the conditions use of these materials in the treatment of polluted water. In order to investigate the efficiency of natural and modified Ghassoul to adsorb glyphosate, the adsorption isotherm was conducted by monitoring the variation of adsorbed amount $Q_{e}\left(\mathrm{mg} \cdot \mathrm{g}^{-1}\right)$ at equilibrium versus equilibrium concentration of adsorbate $\mathrm{C}_{\mathrm{e}}\left(\mathrm{mg} . \mathrm{L}^{-1}\right), \mathrm{Q}_{\mathrm{e}}$ is calculated as follows:

$Q_{e}=\frac{\left(C_{0}-C_{e}\right) V}{m}$

with:

$\mathrm{Q}_{\mathrm{e}}$ : adsorption capacity of glyphosate at equilibrium (mg.g $\left.{ }^{-1}\right)$.

$\mathrm{C}_{0}$ : initial concentration of glyphosate $\left(\mathrm{mg} \cdot \mathrm{L}^{-1}\right)$.

$\mathrm{C}_{\mathrm{e}}$ : glyphosate concentration at equilibrium time $\left(\mathrm{mg} \cdot \mathrm{L}^{-1}\right)$

$\mathrm{m}$ : amount of adsorbent $(\mathrm{g})$

$\mathrm{V}$ : volume of solution (L).

The contact time was fixed at $5 \mathrm{~h}$, which is mostly sufficient to reach an equilibrium condition according to the kinetic study (Fig. 5). The adsorption isotherm revealed that the retention capacity of stevensite increase with the initial concentration (Fig. 10). The obtained isotherms are non-linear and classified as L type according to Gile's classification [45]. The affinity of glyphosate towards Ghassoul surface is high. The adsorption capacity for an initial concentration of $10^{-2} \mathrm{~mol} / \mathrm{L}$, is about $103.15 \mathrm{mg} \cdot \mathrm{g}^{-1}$. The adsorption mechanism should be an interaction between surface silanol and aluminol groups with glyphosate functions. Also, a weak interaction of interlayer water with an amino group of glyphosate should be taken into account ${ }^{46}$.

The surface of the stevensite was then chemically modified by CTAB as long-chain aliphatic surfactant to improve the hydrophobic properties. This category of properties is very important to enhance interaction with non-ionic organic and hydrophobic compound ${ }^{22}$. Indeed, the adsorption isotherm of glyphosate onto the hybrid organoclay reveals an interesting increase in the efficiency of Ghassoul removal properties. The improvement is about $24.57 \%\left(\mathrm{Q}_{\max }=128.49 \mathrm{mg} \cdot \mathrm{g}^{-1}\right)$. This behavior is related to hydrophobic interaction between intercalated CTAB and glyphosate ${ }^{22,47}$. The result has been further drastically improved to $54,24 \%$ $\left(\mathrm{Q}_{\max }=159.10 \mathrm{mg} \cdot \mathrm{g}^{-1}\right)$, in the case of composite StvCts (Fig. 10). The Adsorption increase is closely related to the presence of amine and hydroxyl groups as new potential binding sites. The affinity becomes very higher regarding to the adsorption at low concentration. Figure 11 underlines the high efficiency of this composite to remove glyphosate from aqueous medium. The obtained values are generally higher compared to those cited in the literature, such as $51.1 \mathrm{mg} \cdot \mathrm{g}^{-1}$ for commercial montmorillonite ${ }^{46}, 44.1 \mathrm{mg} \mathrm{g}^{-1}$ for woody biochar ${ }^{48}$. However, the adsorption capacity of $\mathrm{Ni}_{2} \mathrm{AlNO}_{3}$ layered double hydroxide $\left(172.4 \mathrm{mg}_{\mathrm{g}} \mathrm{g}^{-1}\right)$, is more important than that of nanocomposite Stv-Cts ${ }^{49}$. 


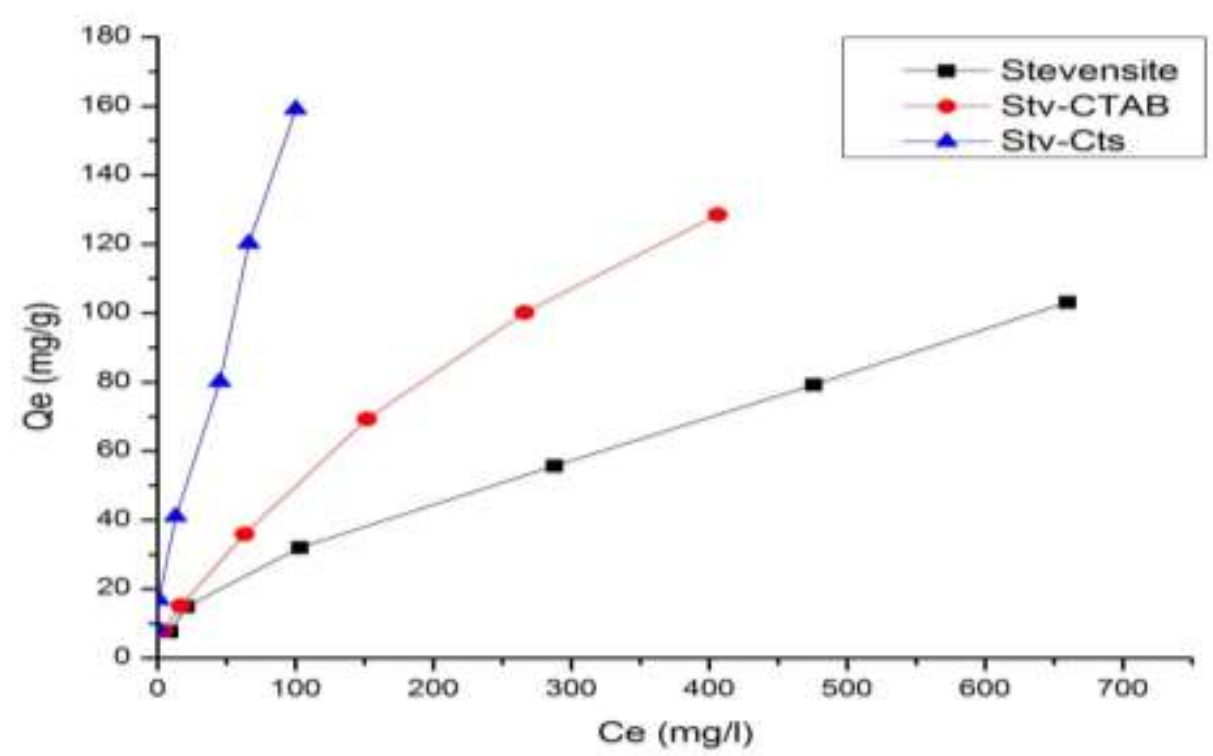

Figure 10. Adsorption isotherms of glyphosate on Stevensite, Stv-CTAB and Stv-Cts

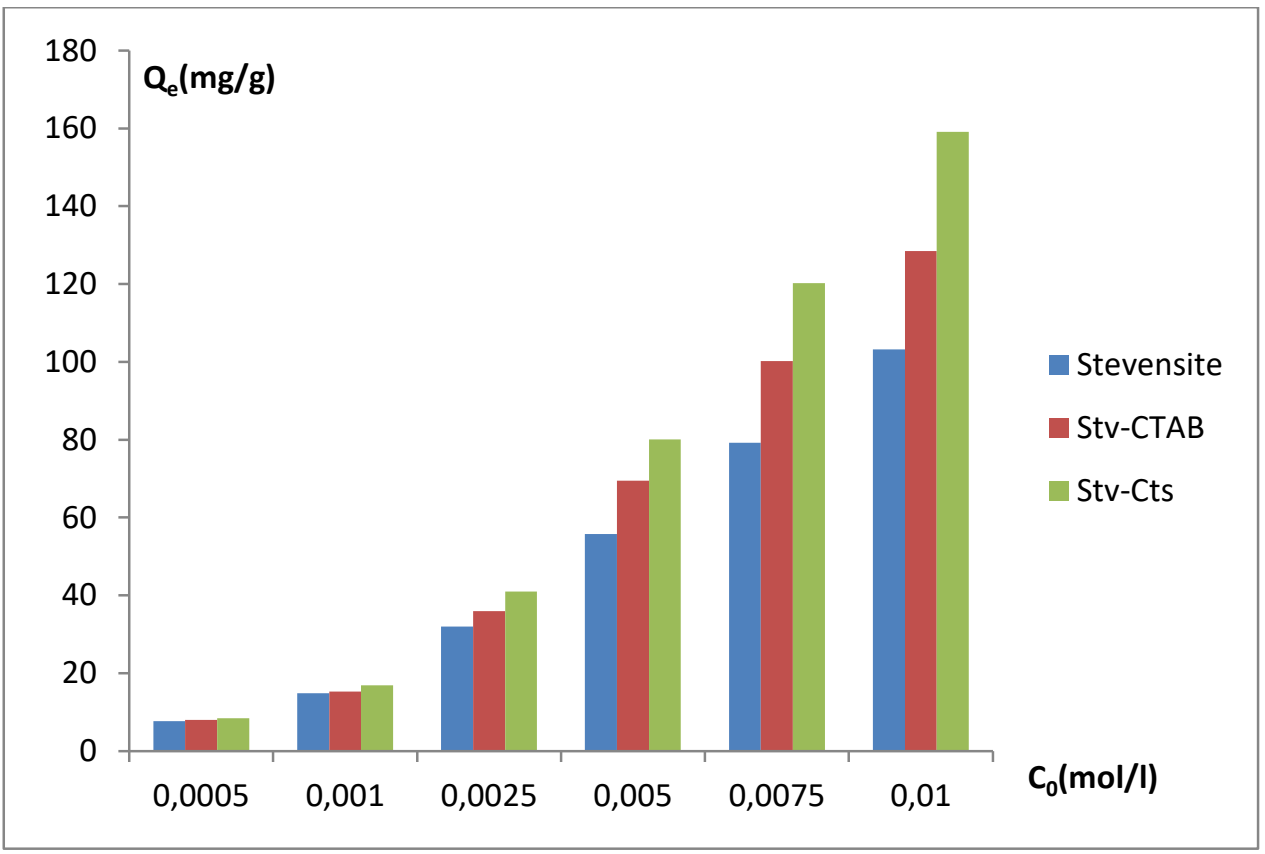

Figure 11. Histogram of glyphosate adsorption on Stevensite, Stv-CTAB and Stv-Cts

The adsorption isotherms were modelled by Langmuir 50, Freundlich ${ }^{51}$ and Temkin 52 equations to investigate the adsorption characteristics of adsorbents.

\subsubsection{Langmuir model}

In the case of Langmuir adsorption equation, the maximum adsorption corresponds to saturation of monolayer of adsorbate molecules onto the adsorbent surface, in the absence of intermolecular interaction. The linear form of the Langmuir isotherm is given by the following equation:

$\frac{C_{e}}{Q_{e}}=\frac{1}{K_{L} Q_{m}}+\frac{C_{e}}{Q_{m}}$
$\mathrm{C}_{\mathrm{e}}$ : equilibrium concentration $\left(\mathrm{mg} \cdot \mathrm{L}^{-1}\right)$

$\mathrm{Q}_{\mathrm{m}}$ : maximum adsorption capacity $\left(\mathrm{mg} \cdot \mathrm{g}^{-1}\right)$ $\mathrm{K}_{\mathrm{L}}$ : Langmuir constant $\left(\mathrm{L} \cdot \mathrm{mg}^{-1}\right)$.

Figure 12 and Table 2 shows that the correlation coefficient $\mathrm{R}^{2}$ is about 0.98 for Stevensite and StvCTAB and 0.96 for Stv-Cts. The maximum adsorption capacities $\mathrm{Q}_{\mathrm{m}}$ calculated from the Langmuir model are relatively higher than experimental data. Therefore, the Langmuir model is not the most appropriate to describe the adsorption isotherm for the raw and modified Ghassoul. 


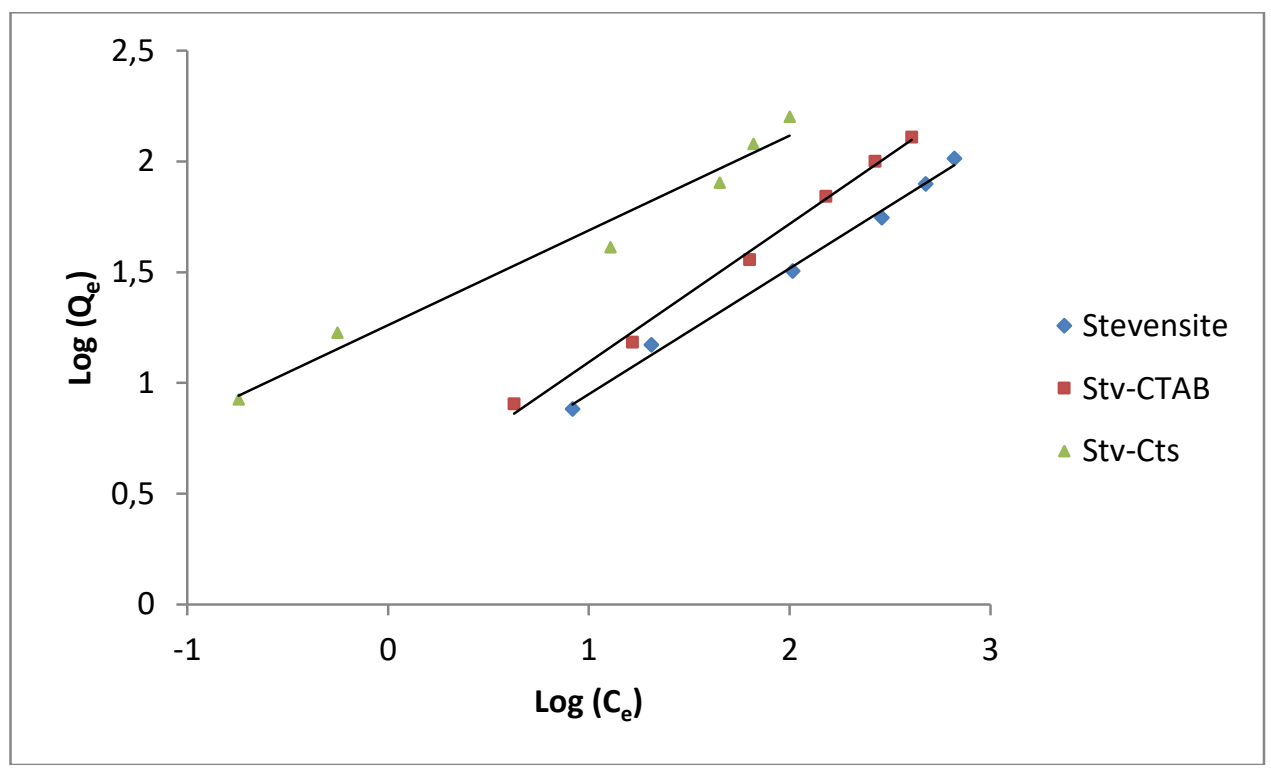

Figure 12. Langmuir isotherms for glyphosate adsorption on Stevensite, Stv-CTAB and Stv-Cts

\subsubsection{Freundlich model}

Freundlich model assumes that adsorption occurs onto the heterogeneous surface. This model is defined by the following equation:

$$
\mathrm{Q}_{\mathrm{e}}=\mathrm{K}_{\mathrm{F}} \mathrm{C}_{\mathrm{e}}^{\frac{1}{\mathrm{n}}}
$$

$$
\ln Q_{e}=\ln K_{F}+\frac{1}{n} \ln C_{e}
$$

Where $\mathrm{K}_{\mathrm{F}}$ and $1 / \mathrm{n}$ are the Freundlich constants related to the adsorption capacity and the strength of adsorption respectively. $\mathrm{C}_{\mathrm{e}}\left(\mathrm{mg} \cdot \mathrm{L}^{-1}\right)$ is the equilibrium concentration.

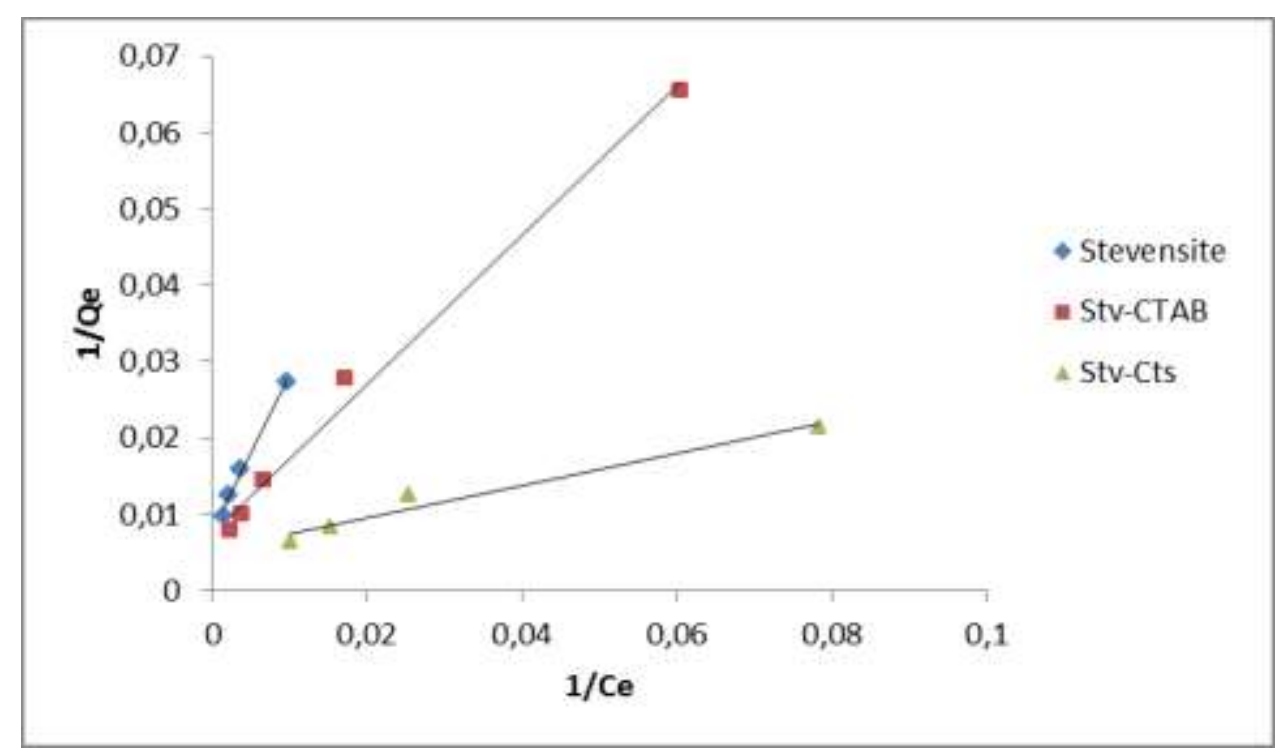

Figure 13. Freundlich isotherms for glyphosate adsorption on Stevensite, Stv-CTAB and Stv-Cts

The values of the constants of Freundlich, $\mathrm{K}_{\mathrm{F}}$ and $1 / \mathrm{n}$, are summarized in Table $2.1 / \mathrm{n}$ values are lower than 1 ; therefore, the adsorption isotherms are of L-type ${ }^{45}$. The coefficients of determination are close to 1 . The Freundlich equation is the most suitable to fit the adsorption isotherm for the three adsorbents (Figure 13).

\subsubsection{Temkin isotherm}

The Temkin isotherm assumes that the decrease in the heat of adsorption is linear with surface saturation and that the adsorption is characterized by the uniform distribution of binding energies. The impact of the concentration is not taken into consideration. Generally, The Temkin isotherm is used in the following form

[44]. 
or in the linear form:

$q_{e}=B \ln K_{T}+B \ln C_{e}$

where $\mathrm{B}=\mathrm{RT} / \mathrm{b}_{\mathrm{t}}\left(\mathrm{J} \cdot \mathrm{mol}^{-1}\right)$, is the Temkin constant

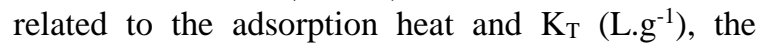
equilibrium constant of adsorption corresponding to the maximum binding energy. The values of the Temkin parameters are summarized in Table 2. This model presents à meagre value of correlation coefficient $\mathrm{R}^{2}$; therefore, the Temkin equation does not fit well glyphosate adsorption data (Fig. 14).

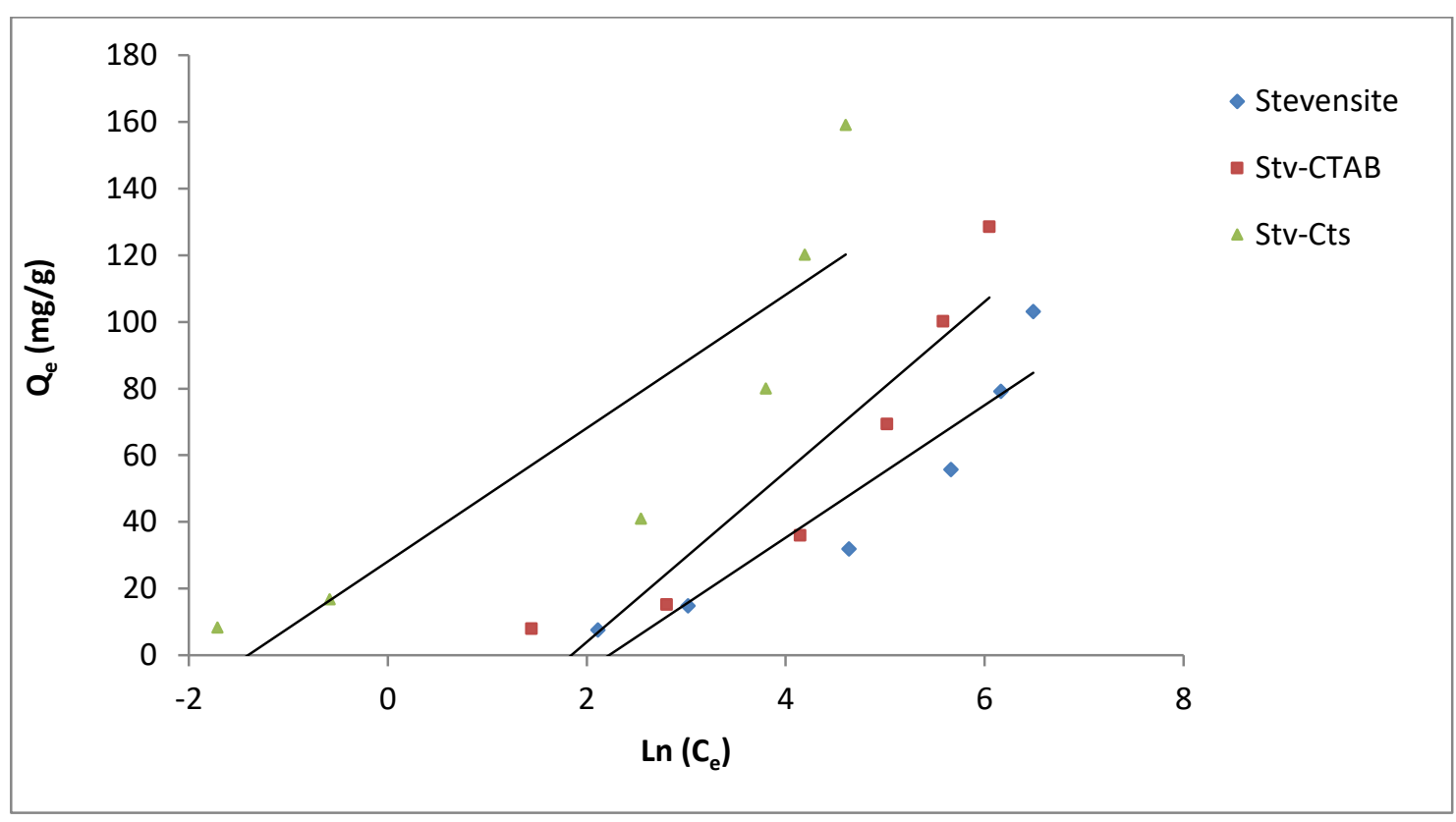

Figure 14. Temkin isotherms for glyphosate adsorption on Stevensite, Stv-CTAB and Stv-Cts

Table 2. Parameters of glyphosate adsorption on the studied materials.

\begin{tabular}{|c|c|c|c|c|}
\hline Models & Parameters & Stevensite & Stv-CTAB & Stv-Cts \\
\hline \multirow[t]{3}{*}{ Langmuir } & $\mathrm{q}_{\max }\left(\mathrm{mg} \cdot \mathrm{g}^{-1}\right)$ & 125,35 & 144.05 & 181.15 \\
\hline & $\mathrm{K}_{\mathrm{L}} \quad\left(\mathrm{L} \cdot \mathrm{mg}^{-1}\right)$ & 0.004 & 0.008 & 0.026 \\
\hline & $\mathrm{R}^{2}$ & 0.98 & 0.98 & 0.96 \\
\hline \multirow[t]{3}{*}{ Freundlich } & $\mathrm{K}_{\mathrm{F}}$ & 2.41 & 2.94 & 18.23 \\
\hline & $\frac{1}{n}$ & 0.57 & 0.63 & 0.43 \\
\hline & $\mathrm{R}^{2}$ & 0.99 & 0.99 & 0.98 \\
\hline \multirow[t]{3}{*}{ Temkin } & $\mathrm{K}_{\mathrm{T}} \quad\left(\mathrm{L} \cdot \mathrm{mg}^{-1}\right)$ & 0.11 & 0.16 & 4.08 \\
\hline & $\mathrm{B} \quad\left(\mathrm{kJ} \cdot \mathrm{mol}^{-1}\right)$ & 19.84 & 25.53 & 19.99 \\
\hline & $\mathrm{R}^{2}$ & 0,88 & 0.87 & 0.79 \\
\hline
\end{tabular}

\section{Conclusion}

In the present research, we successfully carried out a modification of Moroccan Ghassoul clay (Stevensite) with cetyltrimethylammonium bromide (CTAB) surfactant and chitosan (Cts) biopolymer. The CTAB was intercalated in stevensite interlamellar space by a cation exchange reaction, and chitosan by direct interaction with clay sheets. The XRD study revealed a clear increase in the basal space in the case of CTAB $\left(\mathrm{d}_{001}=19.8 \AA\right)$ and chitosan $\left(\mathrm{d}_{001}=17.9 \AA\right)$. This result was corroborated by FT-IR, TG-DTG and TEM. Raw swelling Ghassoul is suitable for the retention of glyphosate as an ionisable herbicide. The adsorption capacity is about $103.15 \mathrm{mg} \cdot \mathrm{g}^{-1}$ for $10^{-2} \mathrm{M}$ initial glyphosate concentration. The adsorption was clearly improved for Stv-CTAB $\left(Q_{\max }=128.49 \mathrm{mg} \cdot \mathrm{g}^{-1}\right)$ and for composite Stv-Cts $\left(Q_{\max }=159.10 \mathrm{mg} \cdot \mathrm{g}^{-1}\right)$. In the case of hybrid organoclay, the interactions are favored by the hydrophobic long-chain alkylammonium of $\mathrm{CTAB}$, whereas in the case of the composite based on chitosan, amine ( $\mathrm{NH} 2)$ and hydroxyl $(\mathrm{OH})$ groups may act as interaction sites with glyphosate. This interaction is very high as expressed by important adsorption at low initial concentration. The adsorption isotherms are well described by the Freundlich model while the pseudo-second-order equation is the most suitable equation for the kinetic mechanism. Ghassoul and its organo-modified materials have then a great potential application in the elimination of ionisable pesticide from contaminated water. Moreover, this fabricated nanocomposite is biodegradable, economic and environmentally friendly.

\section{Acknowledgement}

This work was supported financially by Erasmus Mundus Maghreb, EMMAG and CNRST-Maroc 
(Projets dans les domaines prioritaires de la Recherche Scientifique et du développement technologique PPR2)

\section{References}

1. J. E. Franz, M. K. Mao, J.A. Sikorski, Glyphosate: a unique global herbicide. ACS monograph 189, American Chemical Society, Washington, DC, 1997, p. 653.

2. J. Malik, G. Barry, G. Kishore, The herbicide glyphosate. Biofactors, 1989, 2, 17-25.

3. M. Maroni, C. Colosio, A. Ferioli, A. Fait, Biological Monitoring of Pesticide Exposure: a review. Introduction. Toxicology, 2000, 143, 1118.

4. G. M. Williams, R. Kroes, I. C. Munro, Safety evaluation and risk assessment of the herbicide Roundup and its active ingredient, glyphosate, for humans. Regul Toxicol Pharmacol, 2000, 31 ,117-165

5. C. Cox, Glyphosate, J. Pestic. Reform, 1991,11,2, 35-38.

6. K. Solomon, D. Thompson, Ecological risk assessment for aquatic organisms from overwater uses of glyphosate, J. Toxicol. Environ. Health B, 2003, 6, 3, 289-324.

7. R.A. Relyea, The lethal impact of roundup on aquatic and terrestrial amphibians, Ecol. Appl., 2005, 15, 4, 1118-1124.

8. GHS/CLP-Regulation (EC) No 1272, Annex VI, Table 3-1, List of harmonised classification and labelling of hazardous substances, 2008, pp. 235.

9. T. F. Speth, Glyphosate removal from drinking water, J. Environ. Eng., 1993,119, 1139-1157.

10. Y. Hu, Y. Zhao, B. Sorohan, Removal of glyphosate from aqueous environment by adsorption using water industrial residual, Desalination, 2011, 271, 150-156.

11. S. S. Salih, A. Mahdi, M. Kadhom, T.K. Ghosh, Competitive adsorption of As (III) and As (V) onto chitosan/diatomaceous earth adsorbent; J. Environ. Chem. Eng., 2019, 7, 5, 103407

12. S. S. Salih, T. K. Ghosh, Preparation and Characterization of Chitosan-Coated Diatomaceous Earth for Hexavalent Chromium Removal, Environ. Processes, 2018, 5,1, 23-39.

13. S.S. Salih, T.K. Ghosh, Preparation and characterization of bioadsorbent beads for chromium and zinc ions adsorption. Cogent Environ. Sci. 201, 3, 1, 1401577.

14. A.L. Gimsing, O. K. Borggaard, Phosphate and glyphosate adsorption by hematite and ferrihydrite and comparison with other variablecharge minerals, Clays Clay Miner., 2007, 55, 108-114.

15. A. Gautam, A. Kshirsagar, R. Biswas, S. Banerjee' P. K. Khanna, Photodegradation of organic dyes based on anatase and rutile $\mathrm{TiO}_{2}$ nanoparticles, RSC Adv., 2016,6, 2746-2759

16. S. Azarkan, A. Peña, K. Draoui, C. Ignacio Sainz-Diaz, Adsorption of two fungicides on natural clays of Morocco, App. Clay Sci., 2016, 123, 37-46.

17. M. Ahrouch, J. M. Gatica, K. Draoui, D.

Bellido,' H. Vidal, Lead removal from aqueous solution by means of integral natural clays honeycomb monoliths, J. Hazard. Mater., 2019, 365, 519-530.

18. Y. J. Tang, J .Y. Jia, X .D. Xie, Environment significance of clay minerals. Earth Science Frontiers, 2002, 9, 2, 337-344.

19. Y. Bentahar, C. Hurel, K. Draoui, S. Khairoun, N. Marmier, Adsorptive properties of Moroccan clays for the removal of arsenic(V) from aqueous solution, App. Clay Sci., 2016,119, 385-392

20. L. Bouna, B. Rhouta, F. Maury, A. Jada, F. Senocq and M.C. Lafont Photocatalytic activity of $\mathrm{TiO} 2 /$ stevensite nanocomposites for the removal of Orange $\mathrm{G}$ from aqueous solutions, Clay Miner., 2014, 49, 365-376.

21. R. Ozola, A. Krauklis, J. Burlakovs, M. Klavins, Z. Vincevica-Gaile W. Hogland, Surfactantmodified clay sorbents for the removal of $\mathrm{p}$ nitrophenol, Clays and Clay Miner. 2019, 67, 2, 132-142.

22. H. Azejjel, C. del Hoyo, K. Draoui, M.S. Rodrıguez-Cruz, M.J. Sanchez-Martın, Natural and modified clays from Morocco as sorbents of ionizable herbicides in aqueous medium, Desalination, 2009, 249, 1151-1158.

23. A. Nicoleta, N. Suciu, E. Capri, Adsorption of chlorpyrifos, penconazole and metalaxyl from aqueous solution by modified clays, J. Environ. Sci. Health Part B, 2009, 44, 525-532,

24. M. Rinaudo, Chitin and Chitosan Properties and Applications, Prog. Polym. Sci. 2006, 31, 603632.

25. M. N. Avi Kumar, A review of chitin and chitosan applications React. Funct. Polym., 2000,46, 1-27.

26. S. B. Kim, Y. J. Kim, T. L. Yoon, S. A. Park, I. H. Cho, E. J. Kim, I. A. Kim, J. W. Shin, Biomaterials, The characteristics of hydroxyapatite-chitosan-PMMA bone cement, 2004, 25, 5715-5723.

27. L. Z. Zhao, C. H. Zhou, J. Wang, D. S. Tong, W. H. Yu H. Wang, Recent advances in clay mineral-containing nanocomposite hydrogels, Soft Matter, 2015,11, 9229-9246

28. S.F. Wang, L. Shen, W.D. Zhang, Y.J. Tong, Preparation and mechanical properties of chitosan/carbon nanotubes composites, Biomacromolecules, 2005, 6, 3067-3072.

29. J. Zhang, E. Manias, C.A. Wilkie. Polymerically modified layered silicates: an effective route to nanocomposites, J. Nanosci. Nanotechnol., 2008, 8,1597-615.

30. M. Jaber, J. Miéhé-Brendlé, Formation of organoclays by a one-step synthesis, Solid State Sci. 2005, 7, 5,610-615

31. C. Hu, P. Zhu, M. Caia, H. Hub, Q. Fub Comparative adsorption of $\mathrm{Pb}(\mathrm{II}), \mathrm{Cu}$ (II) and $\mathrm{Cd}(\mathrm{II})$ on chitosan saturated montmorillonite: 
Kinetic, thermodynamic and equilibrium studies, App. Clay Sci., 2017, 143, 320-326.

32. F.A.R. Pereira, K. S. Sousa, G.R.S. Cavalcanti, D.B. França, L.N.F. Queiroga, I.M.G. Santos, M.G. Fonseca, M. Jaber, Green biosorbents based on chitosan-montmorillonite beads for anionic dye removal Journal of Environ. Chem. Engin., 2017, 5, 3309-3318

33. H. Azejjel, J. M. Ordax, K. Draoui, M. S. Rodríguez-Cruz, M. J. Sánchez-Martín, Effect of cosolvents on the adsorption of ethofumesate by modified Moroccan clays, App. Clay Sci., 2010, 49, 120-126

34. B. Rhouta, H. Kaddami., J. Elbarqy, M. Amjoud, L. Daoudi., F. Maury, F. Senocq, A. Maazouz, J. F Gerard, Elucidating the crystal-chemistry of Jbel Rhassoul stevensite (Morocco) by advanced analytical techniques, Clay minerals, 2008, 43, 393-404

35. M. Darder, Mon Colilla, Eduardo Ruiz-Hitzky, Biopolymer-Clay Nanocomposites Based on Chitosan Intercalated in Montmorillonite, Chem. Mater.,2003, 15 ,20 , 3774-3780

36. Y. S. Han, S. H. Lee, K. H. Choi, Preparation and characterization of chitosan-clay nanocomposites with antimicrobial activity, J. of Phys. Chem. Solids, 2010,71,464-467

37. J. Madejova, FTIR techniques in clay mineral studies, Vib. Spectrosc., 2003, 31, 1-10

38. C. Branca, G. D'Angelo, C. Crupi, K. Khouzami, S. Rifici, G. Ruello, U. Wanderlingh, Role of the $\mathrm{OH}$ and $\mathrm{NH}$ vibrational groups in polysaccharide-nanocomposite interactions: A FTIR ATR study on chitosan and chitosan/clay films, Polymer, 2016, 99, 614-622

39. S. Lagergren., B. K. Svenska., Vetenskapsakad. Handl., 1898, 24,1-39.

40. M. Özacar, İ. A. Şengil, Adsorption of reactive dyes on calcined alunite from aqueous solutions, J. Hazard. Mater. 2003, 98, 211-224.

41. Y. S. Ho, G. McKay, Pseudo-second order model for sorption processes, Process Biochem., 1999, 34, 451-465.

42. Y.S. Ho, G. McKay, A multi-stage batch sorption design with experimental data, Adsorpt. Sci. Technol. 1999,17, 233-243
43. M. J. D. Low, Kinetics of chemisorption of gases on solids, Chem. Rev., 1960, 60, 267-312.

44. W.J. Weber, J.C. Morris, Advances in water pollution research: removal of a biologically resistant pollutant from wastewater by adsorption. International Conference on Water Pollution Symposium. Pergamon, Oxford 1962, 2. 231-266

45. C. H. Giles, T. H. MacEwan, S. N. Nakhwa, D. Smith, Studies in adsorption: Part IX. A system of classification of solution adsorption isotherms and its use on the diagnosis of adsorption mechanisms and in the measurement of specific areas of soils. J. Chem. Soc., 1960, 111, 39733993.

46. G. A. Khoury, T. C. Gehris, L. Tribe, R. M. Torres Sánchez, M. S. Afonso, Glyphosate adsorption on montmorillonite: An experimental and theoretical study of surface complexes, App. Clay Sci., 2010, 50,167-175

47. L. Bounab, K. Draoui, M. Ahrouch, M. Hadri, D. Bouchta, A. Barhoun, An effective functionalized Moroccan bentonite: Application for green remediation of $\mathrm{m}$-Cresol, J. Mater. Environ. Sci., 2017, 8, 1, 244-256

48. S.S. Mayakaduwa, P. Kumarathilaka, I. Herath, M. Ahmad, M. Al-Wabel, Y.S. Ok, A. Usman, A. Abduljabbar, M. Vithanage. Equilibrium and kinetic mechanisms of a woody biochar on aqueous glyphosate removal Chemosphere, 2016, 144, 2516-2521

49. A. Khenifi, Z. Derriche, C. Mousty, V. Prévot, C. Forano, Adsorption of Glyphosate and Glufosinate by $\mathrm{Ni}_{2} \mathrm{AlNO}_{3}$ layered double hydroxide Applied Clay Science 2010, 47, 362371

50. I. Langmuir, The adsorption of gases on plane surfaces of glass mica and platinum, J. Am. Chem. Soc. 1918, 40, 1361-1403.

51. H. Freundlich, Ueber die Adsorption in Loesungen. Engelmann, Leipzig. 1906.

52. M. J. Temkin, V. Pyzhev, Recent Modifications to Langmuir Isotherms, Acta Physiochim, URSS, 1940, 12, 217-222. 